\title{
SALIVARY SECRETORY IMMUNOGLOBULIN A LEVEL OF CHILDREN WITH ACUTE LYMPHOBLASTIC LEUKEMIA IN MAINTENANCE PHASE
}

\author{
DANAR PRADIPTA RANI, SARWORINI B BUDIARDJO*, MARGARETHA SUHARSINI
}

Department of Pediatric Dentistry, Faculty of Dentistry, Universitas Indonesia, Jakarta 10430, Indonesia.

Email: Sarworinibagio@yahoo.com

Received: 24 October 2017, Revised and Accepted: 22 November 2017

\section{ABSTRACT}

Objective: The objective of this research is to investigate the differences in salivary secretory immunoglobulin A (sIgA) levels between children with gingivitis who have acute lymphoblastic leukemia (ALL) and are in the maintenance phase of chemotherapy and the levels in healthy children with gingivitis.

Methods: This study used cross-sectional and laboratory observation methods with 19 ALL children and 19 healthy children who all had mild gingivitis. Two $\mathrm{mL}$ of saliva were collected and stored at $-200^{\circ} \mathrm{C}$. Then, salivary sIgA levels were measured using the ELISA method.

Results: The results indicate an insignificant difference ( $p>0.05)$ in salivary sIgA levels between the ALL children in the maintenance phase with the level of 21.38 (7.23-107.26) and 37.26 (11.24-135.63) for the healthy children.

Conclusion: There is no significant difference in salivary sIgA levels between the ALL children in the maintenance phase and the healthy children.

Keywords: Acute lymphoblastic leukemia, Salivary secretory immunoglobulin A, Gingivitis, Maintenance phase.

(C) 2018 The Authors. Published by Innovare Academic Sciences Pvt Ltd. This is an open access article under the CC BY license (http://creativecommons. org/licenses/by/4. 0/) DOI: http://dx.doi.org/10.22159/ajpcr.2018.v11i3.23261

\section{INTRODUCTION}

Leukemia is a malignant disease that originates from blood-forming tissue such as bone marrow, causing many blood cells to be produced and enter the bloodstream. Acute lymphoblastic leukemia (ALL) is the most common type of leukemia [1,2].

Some oral complications found in children with ALL are ulcers, mucosal and spontaneous gingival bleeding, and xerostomia [3]. Secretory immunoglobulin A (SIgA) is one of the immunoglobulins contained in saliva, and it is affected by the systemic state of the body, as evidenced by several studies suggesting a decrease in SIgA in systemic diseases, such as ALL [4].

The main treatment for ALL in children is chemotherapy [5,6]. Research has been done to study the condition of saliva in children with ALL during various phases of treatment, but there has been no research on the level of sIgA saliva during the maintenance phase. Due to this, the authors were interested in examining differences in salivary sIgA levels between children with gingivitis who have ALL and are in the maintenance phase of chemotherapy and the levels in healthy children with gingivitis.

\section{MATERIALS AND METHODS}

\section{Subjects}

This study was performed on 38 children aged 3-16 years who were recruited from the Dharmais Cancer Hospital, Yayasan Kasih Anak Kanker Indonesia, the Pediatric Dentistry Clinic Faculty of Dentistry Universitas Indonesia, and the Oral Laboratory Faculty of Dentistry Universitas Indonesia. The subjects were divided into two groups, one consisting of 19 children with ALL and one consisting of 19 healthy children. All subjects had to be in a normal weight range according to Kartu Menuju Sehat, and all had mild gingivitis with a score of 1-2 on Lobene modified gingival index. The subjects and their parents received verbal and written information about the study and given consent forms. Dental examinations were conducted by one trained examiner for all subjects.

The study design, protocol, and informed consent were approved by the Ethics Committee of the Faculty of Dentistry Universitas Indonesia. The procedures, possible discomforts or risks, and potential benefits were fully explained to the subjects and their parents. Written informed consent was obtained from the parents of all children enrolled in this study before the investigation.

\section{Methods}

This study was a laboratory observation using a cross-sectional method. The sample was saliva collected from study participants between 08.00 and 11.00 in the morning. The subject was asked to accumulate saliva in the floor of the mouth, and then, the saliva was taken with a sterile pipette. Whole saliva was collected in a sterile sample separator tube. About $2 \mathrm{~mL}$ of saliva was collected. The sample was stored at $-200^{\circ} \mathrm{C}$ until it was analyzed. The ELISA method was used to make a quantitative determination of salivary sIgA levels using a salivary secretory IgA kit from Salimetric LLC, USA.

\section{Statistical analysis}

The Mann-Whitney $U$-test was used to compare salivary sIgA levels in children with ALL and healthy children.

\section{RESULTS}

There were 38 subjects in this study ranging from 3 to 16 years of age, all with mild gingivitis, in accordance with the inclusion criteria. The sample consisted of 19 children with ALL in the maintenance phase and 19 healthy children.

The Shapiro-Wilk normality test indicated the abnormal distribution of saliva sIgA levels in the children in the maintenance phase of treatment for ALL and the healthy children. Similarly, the statistical analysis using the Mann-Whitney test had a significance of $p \leq 0.05$. Table 1 shows that 
Table 1: Difference between salivary sIgA levels in children with ALL in the maintenance phase and with gingivitis and SIgA levels in healthy children with gingivitis

\begin{tabular}{lll}
\hline Salivary sIgA level & $\begin{array}{l}\text { Median } \\
\text { (Minimum-maximum) } \\
(\mu \mathrm{g} / \mathrm{ml})\end{array}$ & p value \\
\hline $\begin{array}{l}\text { Children with ALL in } \\
\text { maintenance phase }(\mathrm{n}=19)\end{array}$ & $21.38(7.23-107.26)$ & 0.157 \\
Healthy children $(\mathrm{n}=19)$ & $37.26(11.24-135.63)$ & \\
\hline
\end{tabular}

Mann-Whitney test; *Significance level based on $\mathrm{p}<0.05$. sIGA: Secretory

immunoglobulin A, ALL: Acute lymphoblastic leukemia

there was an insignificant difference in salivary sIgA levels between children with ALL and healthy children ( $p>0.05$ ).

\section{DISCUSSION}

This study was conducted at the Dharmais Cancer Hospital, Yayasan Kasih Anak Kanker Indonesia, the Pediatric Dentistry Clinic of the Faculty of Dentistry Universitas Indonesia, and the Oral Biology Laboratory of the Faculty of Dentistry Universitas Indonesia. The Dharmais Cancer Hospital is a special referral hospital for cancer in Jakarta, and during the past 9 years, has reported that leukemia was the most common type of childhood cancer treated in the facility. Since 2014, there have been 46 new leukemia patients admitted to this hospital.

The age range of 3-16 years old was selected based on the previous studies. IgA-producing plasma cells are not found in the mucosa before the age of 10 days but then increase rapidly in the $1^{\text {st }}$ month of life $[7,8]$. There is an increase in sIgA levels during the first 4 years of life, and these levels increase dramatically by the age of 5 years. The sIgA level then drops back and remains constant after the age of 7 , and there is no significant difference in sIgA levels in those between 15 and 70 years of age. Other studies have shown that saliva is stable between the ages of 10 and 12 years $[9,10]$.

Saliva collection was limited to between the hours of 08.00 and 11.00 in the morning, WIB, as it was between breakfast and lunch. Subjects were asked not to eat an hour before saliva collection to minimize bias due to salivary stimulation [11,12]. This time span was also selected to prevent SIgA level bias due to the influence of circadian rhythms $[13,14]$. Based on a previous study, it is known that the highest salivary sIgA concentrations are in the morning and levels decrease to their lowest value at the night [15-17]. In addition, salivary flow rate is higher at the night than in the morning and is inversely proportional to IgA concentration. This is due to more sympathetic nervous activity in the morning than at any other time, and increased sympathetic activity reduces salivary flow rate. Saliva taken in this study was unstimulated saliva because sIgA levels in stimulated saliva are lower than in unstimulated saliva [18-20].

The design of this study was cross-sectional. Collection of saliva samples was done one at a time, and the sIgA level was then measured from the saliva sample. In medical research, cross-sectional studies are one of the most commonly used forms of observational studies. The advantage of this type of the study is that it is relatively cheap, easy, and quick to obtain the results. However, this study could not describe the disease because it was only taken once [21-23].

Based on the Mann-Whitney test, it was known that there was an insignificant difference in salivary sIgA levels between children with ALL and normal children. These results were consistent with thecearlier studies that reported salivary sIgA levels in children with ALL were lower than levels in healthy children. It is known that sIgA levels can decrease due to the cancer itself and can continue decreasing for up to 6 months. Anticancer therapy is considered to be ineffective in reducing sIgA levels, but other studies have found that chemotherapy drugs do cause a decrease in salivary sIgA levels $[3,34]$. The decrease of salivary sIgA levels can also be due to immunosuppression in B cells, which then affects functional products such as IgG, IgM, and IgA. The decrease in sIgA levels not only affects salivary antimicrobial activity but also the salivary antioxidant capacity, thus making the oral mucosa susceptible to injury and infection [24].

The previous studies have demonstrated that the cellular and humoral immune systems will return to normal after antineoplastic therapy is completed. The level of immunoglobulin in children with ALL will increase 6-7 months after the onset of chemotherapy [23]. Researchers noted that salivary sIgA levels would return to normal after the maintenance phase was over and for as long as 5 years after chemotherapy was completed. This was seen from the salivary sIgA levels of the children with ALL in this study. The tendency of a return to normal salivary sIgA levels in children with ALL was shown in this study by the lack of significant differences in sIgA levels between the children with ALL and the healthy children even though both groups entered the study with the same inflammatory conditions.

\section{CONCLUSION}

It can be concluded that there is no significant difference between salivary sIgA levels of children with ALL and healthy children, even with the generally lower salivary sIgA levels in the children with ALL.

\section{ACKNOWLEDGMENT}

The Publication of the manuscript is supported by Universitas Indonesia in 2017. This study was designed, conducted, and coordinated by Professor Sarworini B. Budiardjo and Professor Margaretha Suharsini as the principal investigator, provided conceptual and ethical guidance for all aspect of the project. Danar Pradipta Rani performed, analyzed the data, and write the manuscript.

\section{CONFLICT OF INTEREST}

There is no conflict of interest

\section{REFERENCES}

1. Gomes MF, Kohlemann KR, Plens G, Silva MM, Pontes EM, da Rocha JC, et al. Oral manifestations during chemotherapy for acute lymphoblastic leukemia: A case report. Quintessence Int 2005;36:30713.

2. Gupta JM, Dahiya RK, Dureja MH. Therapies in cancer treatment: An overview. Int J Pharm Pharm Sci 2015;7:1-9.

3. Antony A, Joel JJ, Shetty J, Umar NF. Identification and analysis of adverse drug reactions associated with cancer chemotherapy in hospitalized patients. Int J Pharm Pharm Sci 2016;8:448-51.

4. Hegde AM, Joshi S, Rai K, Shetty S. Evaluation of oral hygiene status, salivary characteristics and dental caries experience in acute lymphoblastic leukemic (ALL) children. J Clin Pediatr Dent 2011;35:319-23

5. Basir L, Mandali F, Abaforoush T, Jaseb K, Badiee M. Evaluation the effect of IL-6, s-IGA, pH and salivary flow rate on dental caries in children with acute lymphoblastic leukemia. Int J Comp Lead Res Sci 2015; $1: 65-78$

6. Azher U, Shiggaon N. Oral health status of children with acute lymphoblastic leukemia undergoing chemotherapy. Indian J Dent Res 2013;24:523.

7. Ponce-Torres E, Ruíz-Rodríguez Mdel S, Alejo-González F, HernándezSierra JF, Pozos-Guillén Ade J. Oral manifestations in pediatric patients receiving chemotherapy for acute lymphoblastic leukemia. J Clin Pediatr Dent 2010;34:275-9.

8. Rashkova M, Baleva M, Toneva N, Jegova G. Secretory immunoglobulin $\mathrm{A}(\mathrm{sIgA})$ and periodontal status in children with diseases and conditions influencing the oral environment. J IMAB 2009;2:36-40.

9. Handajani J, Azmara W, Tandeliln RTC. Efekekstrakdaunteh (Camellia sinensis) konsentrasi $0,5 \%$ terhadapkadarsIg apada saliva penderita gingivitis. J Dent Ind 2004;11:17-23.

10. Karolewska E, Konopka T, Pupek M, Chybicka A, Mendak M, Antibacterial potential of saliva in children with leukemia. Oral Surg Oral Med Oral Pathol Oral Radiol Endod 2008;105:739-44.

11. Coico R, Sunshine G. Immunology: A Short Course. West Sussex: John 
Wiley and Sons; 2015.

12. Amerongen AV. Ludahdankelenjarludah: Artibagikesehatangigi. Yogyakarta: Gadjah Mada University Press; 1991. p. 77-89.

13. Nisengard R, Newman MG. Oral Microbiology and Immunology. Philadelphia: WB Saunders; 1994.

14. Lamont RJ, Jenkinson HF. Oral Microbiology at a Glance. Oxford: Wiley Blackwell; 2010. p. 8-13.

15. Walker DM. Oral mucosal immunology: An overview. Ann Acad Med Singapore 2004;33:27-30

16. Shifa S, Muthu MS, Amarial D, Prabhu VR. Quantitative assessment of IgA levels in the unstimulated whole saliva of caries-free and cariesactive children. J Indian Soc Pedod Prev Dent 2008;26:158-61.

17. Reid MM, Craft AW, Cox JR. Immunoglobulin concentrations in children receiving treatment for acute lymphoblastic leukaemia. J Clin Pathol 1981;34:479-82.

18. Abrahamsson J, Marky I, Mellander L. Immunoglobulin levels and lymphocyte response to mitogenic stimulation in children with malignant disease during treatment and follow-up. Acta Paediatr
$1995 ; 84: 177-82$

19. Sun H, Chen Y, Zou X, Li Q, Li H, Shu Y, et al. Salivary secretory immunoglobulin (SIgA) and lysozyme in malignant tumor patients. Biomed Res Int 2016;2016:8701423.

20. Otsuki T, Sakaguchi H, Hatayama T, Takata A, Hyodoh F, Tsujita S, et al. Secretory igA in saliva and academic stress. Int J Immunopathol Pharmacol 2004;17:45-8

21. Maclaughlin BW, Wang D, Noone AM, Liu N, Harazduk N, Lumpkin $\mathrm{M}$, et al. Stress biomarkers in medical students participating in a mind body medicine skills program. Evid Based Complement Alternat Med 2011;2011:950461.

22. Trochimiak T, Hübner-Woźniak E. Effect of exercise on the level of immunoglobulin a in saliva. Biol Sport 2012;29:255-61.

23. Timmons BW. Exercise and immune function in children. Am J Life Med 2007;1:59-66.

24. Brandtzaeg P. Mucosal immunity: Induction, dissemination, and effector functions. Scand J Immunol 2009;70:505-15. 